\title{
Virology, RNA Viruses
}

National Cancer Institute

\section{Source}

National Cancer Institute. Virology, RNA Viruses. NCI Thesaurus. Code C19120.

Research concerned with the origin, structure, development, growth, function, genetics, and reproduction of RNA viruses. 